\title{
Evaluation of in-stent restenosis in the APPROACH trial (assessment on the prevention of progression by Rosiglitazone on atherosclerosis in diabetes patients with cardiovascular history)
}

\author{
Héctor M. García-García • Scot Garg • Salvatore Brugaletta • Giorgio Morocutti • \\ Robert E. Ratner • Nikheel S. Kolatkar • Barbara G. Kravitz • Diane M. Miller • \\ Chun Huang • Richard W. Nesto $\cdot$ Patrick W. Serruys - The APPROACH study group
}

Received: 5 October 2010/ Accepted: 16 February 2011/Published online: 27 February 2011

(C) The Author(s) 2011. This article is published with open access at Springerlink.com

\begin{abstract}
To determine (1) the medium-term effect of rosiglitazone and glipizide on intra-stent neointima hyperplasia, (2) restenosis pattern as assessed by intravascular ultrasound (IVUS) and quantitative coronary angiography (QCA) in patients with T2DM and coronary artery disease. A total of 462 patients with T2DM were randomized to rosiglitazone or glipizide for up to 18 months in the APPROACH trial, and had evaluable baseline and follow-up IVUS examinations. There was no significant difference in the size of plaque behind stent between the rosiglitazone and glipizide groups at 18 months among those treated with a bare metal stent $\left(-5.6 \mathrm{~mm}^{3}\right.$ vs. $\left.1.9 \mathrm{~mm}^{3} ; P=0.61\right)$ or with a drug-eluting stent $\left(12.1 \mathrm{~mm}^{3}\right.$ vs. $\left.5.5 \mathrm{~mm}^{3} ; P=0.09\right)$. Similarly, there was no significant difference in
\end{abstract}

Trial Registration: Clinicaltrials.gov NCT00116831. http://clinicaltrials.gov/ct2/show/NCT00116831.

The members of the APPROACH study group are given in "Appendix".

H. M. García-García ( $₫)$ · S. Garg · S. Brugaletta · P. W. Serruys

Erasmus Medical Center, Z120 Thoraxcentre,

Gravendijkwal 230, 3015 CE Rotterdam, The Netherlands

e-mail: h.garciagarcia@erasmusmc.nl

H. M. García-García

Cardialysis, Rotterdam, The Netherlands

G. Morocutti

Cardiologia, Azienda Ospedaliera, Universitaria S. Maria

della Misericordia, Udine, Italy percentage intimal hyperplasia volume between the rosiglitazone and glipizide groups at 18 months among those treated with a bare metal stent $(24.1 \%$ vs. $19.8 \%$; $P=0.38)$ or with a drug-eluting stent $(9.8 \%$ vs. $8.3 \%$; $P=0.57$ ). QCA data (intra-stent late loss, intra-stent diameter stenosis or binary restenosis) were not different between the rosiglitazone and glipizide groups. This study suggests that both rosiglitazone and glipizide have a similar effect on neointimal growth at medium term follow-up, a finding that warrants investigation in dedicated randomized trials.

Keywords Restenosis - Type 2 diabetes - IVUS . Atherosclerosis

\section{Introduction}

The APPROACH (Assessment on the Prevention of Progression by Rosiglitazone On Atherosclerosis in diabetes patients with Cardiovascular History) study

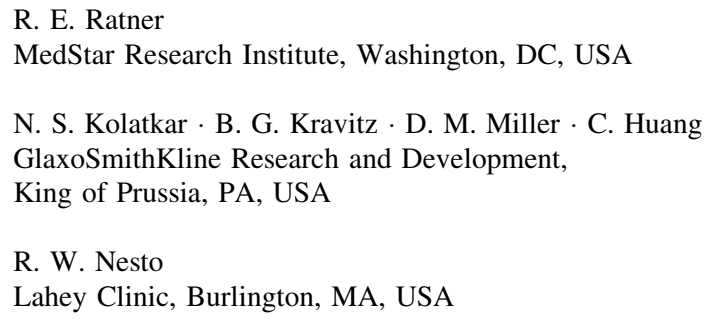


was a double-blind randomized clinical trial comparing the effects of rosiglitazone with glipizide on the progression of coronary atherosclerosis [1, 2]. Patients with Type 2 diabetes mellitus (T2DM) are at increased risk for restenosis after intracoronary stent placement [3-6]. Moreover, prior studies have suggested that thiazolidinediones, which improve insulin sensitivity and have effects on vascular smooth muscle cell proliferation and neointimal hyperplasia, may reduce rates of in-stent restenosis in patients irrespective of their diabetic status [7-15].

The objectives of this pre-specified APPROACH sub-study were: (1) to determine the effect of rosiglitazone and glipizide on intra-stent neointima hyperplasia in patients with T2DM and coronary artery disease (CAD); (2) to determine the restenosis parameters measured by intravascular ultrasound (plaque behind stent, intra-stent intima hyperplasia volume); and (3) to report the quantitative coronary angiography (QCA) intra-stent late loss, intra-stent diameter stenosis [DS], and binary angiographic restenosis.

\section{Materials and methods}

Study design and eligibility criteria

A detailed description of the APPROACH trial has been previously published [1]. In brief, the APPROACH study was a prospective multicenter, double-blind, randomized, active-controlled trial (Fig. 1) of 672 patients from 92 centers in 19 countries, who were aged $30-80$ years with established T2DM and who had clinically indicated coronary angiography or percutaneous coronary intervention (PCI) between February 2005 and January 2007. Patients were included if they had at least one atherosclerotic plaque with $>50 \%$ luminal narrowing in a coronary artery, and if their diabetes was treated with either lifestyle approaches alone (with an HbA1C $>7$ and $\leq 10 \%$ ), or with oral agents comprising 1 oral agent at any dose, or 2 oral agents where each was prescribed at $\leq 50 \%$ of its maximal dose (with an $\mathrm{HbA1C}>6.5$ and $\leq 8.5 \%$ ). Exclusion criteria were: ST-segment elevation myocardial infarction in the prior 30 days; coronary artery bypass graft surgery; severe valvular heart disease; left ventricular ejection fraction $<40 \%$; any heart failure (New York Heart Association class I-IV); uncontrolled hypertension (systolic blood pressure $>170$ $\mathrm{mmHg}$ or diastolic blood pressure $>100 \mathrm{mmHg}$ ); renal insufficiency (serum creatinine $\geq 1.5 \mathrm{mg} / \mathrm{dl}$ for men or $\geq 1.4 \mathrm{mg} / \mathrm{dl}$ for women); and active liver disease. Participant safety was monitored by an Independent Data Monitoring. Data analysis was performed according to a pre-specified plan that was developed with the approval of the steering committee.

In this pre-specified analysis, all patients who underwent stent placement during APPROACH and

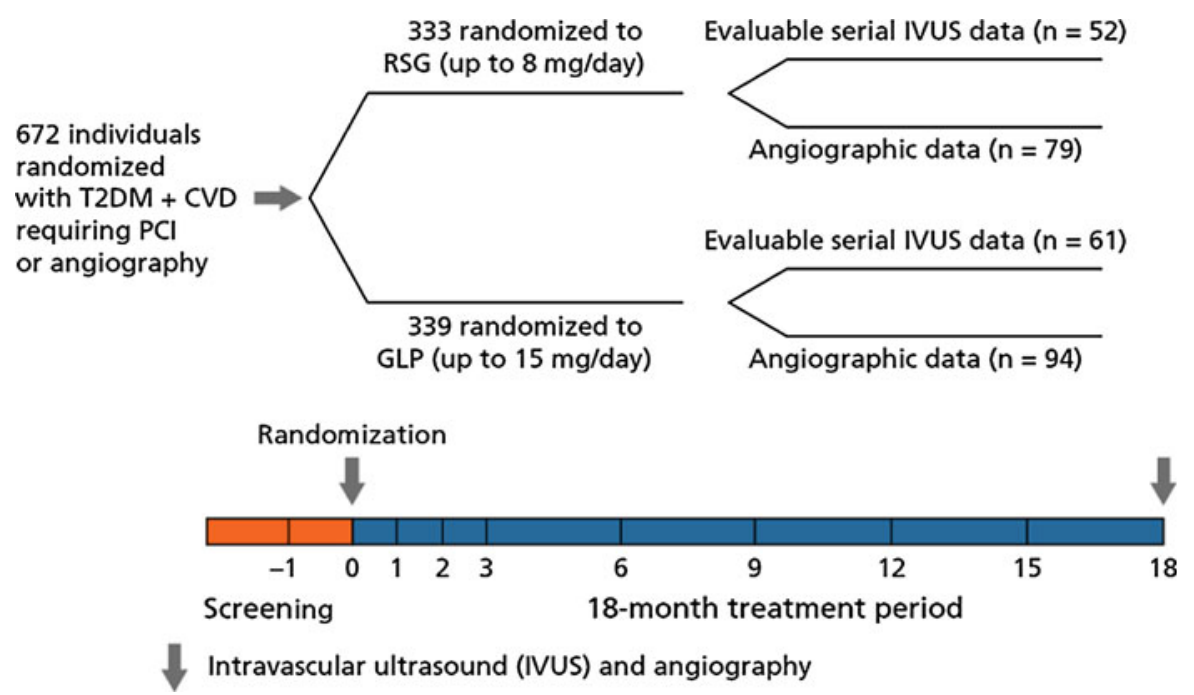

Fig. 1 Patient disposition. $C V D$ cardiovascular disease, GLP glipizide, IVUS intravascular ultrasound, $P C I$ percutaneous coronary intervention, $R S G$ rosiglitazone, $T 2 D M$ type 2 diabetes mellitus 
had available serial IVUS or QCA measurements were included.

Quantitative angiography analysis

The angiograms were stored in DICOM format and analyzed offline by Core laboratory personnel (Cardialysis, Rotterdam, The Netherlands), using the CASS II analysis system (Pie Medical BV, Maastricht, The Netherlands). The following quantitative coronary angiography (QCA) analysis parameters were measured: computed-defined minimal luminal diameter (MLD) and reference vessel diameter (RVD) obtained by an interpolate method.

\section{Quantitative coronary angiography endpoints}

Late loss was defined as the difference in minimum lumen diameter between baseline and follow-up.

Percent diameter stenosis was defined as the minimum lumen diameter divided by the reference vessel diameter at the site of the MLD $\times 100$.

Binary angiographic restenosis was defined as follow-up stenosis $>50 \%$. This is reported as frequency and percentage.

Management of glycemia and follow-up

Patients were randomized in a $1: 1$ ratio to receive masked rosiglitazone (4 mg/day) or glipizide $(5 \mathrm{mg}$ / day) in one pill. After 2 and 3 months, the dose of masked study drug was increased if tolerated and if the mean daily glucose level calculated from the patient's logbook of capillary tests in the 3 days prior to the visit was $\geq 126 \mathrm{mg} / \mathrm{dl}(7.0 \mathrm{mmol} / \mathrm{l})$. If more than 1 titration was required, 2 pills per day were given. Open-label metformin (maximal total daily dose $2,550 \mathrm{mg}$ ) and then once-daily basal insulin, or both was added after the first 3 months if needed to maintain a HbAlc $\leq 7 \%$ using a glycemic titration algorithm designed to provide comparable glycemic control between treatment groups. Non-study drugs were reduced before study drugs in the event of hypoglycemia requiring dose reductions. Unless informed consent was formally withdrawn, all patients were followed until 18 months from randomization and clinical status ascertained regardless of whether they continued to take study medication.
Intravascular ultrasound examination and image analysis

Following stent implantation IVUS was performed. After intracoronary administration of nitroglycerin, an ultrasound catheter (2.5F Atlantis SR Pro Imaging $40 \mathrm{MHz}$ ) connected to a Galaxy G2 digital imaging console (Boston Scientific, Natick, MA) was advanced into the target vessel. The imaging transducer was positioned just distal to an identifiable side branch, and then motorized pullback of the transducer was performed at $0.5 \mathrm{~mm} / \mathrm{s}$. If a participant required cardiac catheterization for a clinical indication between 9 and 18 months, follow-up IVUS examination could be performed at that time instead of at study completion.

Intravascular ultrasound outcomes

Core laboratory personnel (Cardialysis, Rotterdam, The Netherlands) who were blinded to treatment assignment analyzed all IVUS images using validated software (Curad, version 3.1, Wijk bij Duurstede, The Netherlands), that facilitates detection of luminal and external elastic membrane (EEM-also called vessel contour) boundaries in reconstructed longitudinal planes. In order to obtain a smooth appearance of the vessel wall structures in the longitudinal views, the Intelligate ${ }^{\mathrm{TM}}$ image-based gating method was applied [16, 17].

\section{Intravascular ultrasound endpoints}

Plaque behind stent was derived by subtracting the mean stent area from the vessel mean area.

Percentage volume of intimal hyperplasia (\% $\% \mathrm{vol}$ IH) was defined as IH volume divided by stent volume.

\section{Statistical methods}

For baseline characteristics, continuous variables are expressed as mean and standard deviation, or median and interquartile range if non-normally distributed, with categorical variables reported as percentage. For continuous variables $P$ values were based on Wilcoxon test, while for categorical variables $P$ values were based on Fisher's exact test. The $P$ values for treatment difference of continuous IVUS and QCA 
variables were based on analysis of covariance model (ANCOVA) with terms for treatment, baseline measurement, region, gender, cardiac procedure, and prior OAD medication. Two sample test was used for group comparisons at baseline and follow-up. For binary angiographic restenosis, Fisher's exact test was used.

\section{Results}

\section{Participants}

In total $672(68 \%$ men) of mean (SD) age 61 (9) years, median diabetes duration of 4.8 years and mean haemoglobin HbA1C of 7.2 (0.9) \% were randomized to either glipizide $(N=339)$ or rosiglitazone $(N=333)$ from 92 sites in 19 countries (Fig. 1). At the end of the study, 462 randomized patients had evaluable baseline and follow-up IVUS examinations. 173 had evaluable angiographic data and 113 had serial IVUS data from a vessel with PCI at baseline.

Patients were followed for a median of 18.6 months (IQR 18.2-18.9) and a mean (SD) of 16 (6) months; patients allocated to glipizide were adherent at $90.7 \%$ of visits and those allocated to rosiglitazone were adherent at $92.7 \%$ of visits.

In this analysis, 231 patients who underwent stent placement during the study and had available serial IVUS or QCA measurements were included. Patients who underwent stent placement do not represent randomized groups, however the distribution of these patients was similar between the randomized groups (glipizide $N=118$, rosiglitazone $N=113$ ).

Baseline characteristics were generally similar between the groups. (Table 1). Patients in the rosiglitazone group had slightly higher serum creatinine, compared with glipizide $(P=0.01)$.

All the DES implanted were from 1st DES generation. No difference in stent size were found between groups (Table 2).

Effect on intravascular ultrasound endpoints

There was no significant difference in the size of plaque behind stent between the rosiglitazone and glipizide groups at 18 months among those treated with a bare metal stent $\left(-5.6 \mathrm{~mm}^{3}\right.$ vs. $\left.1.9 \mathrm{~mm}^{3} ; P=0.61\right)$ or with a drug-eluting stent $\left(12.1 \mathrm{~mm}^{3}\right.$ vs. $\left.5.5 \mathrm{~mm}^{3} ; P=0.09\right)$ (Table 3). Similarly, there was no significant difference in percentage intimal hyperplasia volume between the rosiglitazone and glipizide groups at 18 months among those treated with a bare metal stent $(24.1 \%$ vs. $19.8 \%$; $P=0.38)$ or with a drug-eluting stent $(9.8 \%$ vs. $8.3 \%$; $P=0.57)$ (Table 3).

\section{Effect on QCA endpoints}

Intra-stent late loss did not differ between the rosiglitazone and glipizide groups among those with a bare metal stent $(0.76 \mathrm{~mm}$ vs. $0.71 \mathrm{~mm} ; P=0.51)$ or a drug-eluting stent $(0.37$ vs. $0.25 ; P=0.41)$ (Table 3). There was no difference in intra-stent diameter stenosis between the rosiglitazone and glipizide groups among those with a bare metal stent (32.3\% vs. $30.4 \% ; P=0.50$ ) or a drug-eluting stent (22.1\% vs. $17.9 \%$; $P=0.28$ ) (Table 3 ). The percentage of patients with binary angiographic restenosis did not differ between the rosiglitazone and glipizide groups among those with a bare metal stent (22.9\% vs. $10.8 \% ; P=0.21)$ or a drug-eluting stent (4.6\% vs. $1.8 \% ; P=0.58$ ) (Table 3 ).

\section{Safety}

As noted previously, the patients who underwent stent placement do not represent randomized groups, however, there were no significant differences in cardiovascular events between the rosiglitazone and glipizide groups, which occurred infrequently during the trial (Table 4).

In the rosiglitazone group, 5 cardiovascular events occurred within 5 days of the baseline cardiac catheterization and were classified as procedurerelated. These events included one revascularization, two nonfatal myocardial infarctions, one nonfatal stroke and one cardiovascular death.

\section{Discussion}

This study demonstrates no additional advantage of using rosiglitazone over glipizide in Type 2 diabetic patients for the reduction of in-stent restenosis; however it did demonstrate that both drugs have comparable effect on neointimial growth up to 18-months after coronary stent implantation. 
Table 1 Baseline characteristics of intervened patients

\begin{tabular}{|c|c|c|c|}
\hline & Glipizide $(N=118)$ & Rosiglitazone $(N=113)$ & $\mathrm{P}$ value \\
\hline \multicolumn{4}{|l|}{ Demographic characteristics } \\
\hline Age, mean (SD), years & $60.4(9.1)$ & $62.4(8.1)$ & 0.14 \\
\hline Male, $n(\%)$ & $84(71.2 \%)$ & $92(81.4 \%)$ & 0.09 \\
\hline Weight, mean (SD), kg & $81.9(17.5)$ & $80.2(17.3)$ & 0.56 \\
\hline BMI, mean (SD), $\mathrm{kg} / \mathrm{m}^{2}$ & $29.2(4.9)$ & $28.7(5.3)$ & 0.30 \\
\hline Duration of diabetes, median [IQR], years & $4.5[1.5-9.5]$ & $4.5[1.9-8.7]$ & 0.77 \\
\hline Hypertension, $n(\%)$ & $91(77.1 \%)$ & $88(77.9 \%)$ & 1.00 \\
\hline Dyslipidemia, $n(\%)$ & $72(61.0 \%)$ & $74(65.5 \%)$ & 0.50 \\
\hline Prior myocardial infarction, $n(\%)$ & $38(32.2 \%)$ & $28(24.8 \%)$ & 0.24 \\
\hline \multicolumn{4}{|l|}{ Presenting condition, $n(\%)$} \\
\hline Acute coronary syndrome & $60(50.9 \%)$ & $55(48.7 \%)$ & \multirow[t]{2}{*}{0.79} \\
\hline Elective procedure & $58(49.2 \%)$ & $58(51.3 \%)$ & \\
\hline \multicolumn{4}{|l|}{ Baseline procedure, $n(\%)$} \\
\hline Coronary angiography & $6(5.1 \%)$ & $6(5.3 \%)$ & \multirow[t]{2}{*}{1.00} \\
\hline Percutaneous coronary intervention & $112(94.9 \%)$ & $107(94.7 \%)$ & \\
\hline Current smoker, $n(\%)$ & $20(17.0 \%)$ & $24(21.2 \%)$ & 0.50 \\
\hline \multicolumn{4}{|l|}{ ACC/AHA lesion type, $n(\%)$} \\
\hline A & $14(11.7)$ & $14(12.1)$ & \multirow[t]{4}{*}{0.53} \\
\hline B1 & $49(41.5)$ & $48(42.6)$ & \\
\hline B2 & $35(29.7)$ & $32(28.3)$ & \\
\hline $\mathrm{C}$ & $20(17.1)$ & $19(17.0)$ & \\
\hline \multicolumn{4}{|l|}{ Prior medication use } \\
\hline Aspirin & $106(89.8 \%)$ & $102(90.3 \%)$ & 1.00 \\
\hline Other anti-platelet & $109(92.4 \%)$ & $108(95.6 \%)$ & 0.41 \\
\hline Beta-blocker & $88(74.6 \%)$ & $86(76.1 \%)$ & 0.88 \\
\hline $\mathrm{ACE}$ inhibitor or $\mathrm{ARB}$ & $80(67.8 \%)$ & $71(62.8 \%)$ & 0.49 \\
\hline Nitrates & $57(48.3 \%)$ & $56(49.6 \%)$ & 0.90 \\
\hline Statin & $97(82.2 \%)$ & $94(83.2 \%)$ & 0.86 \\
\hline Fibrate or other lipid-lowering agent & $7(5.93 \%)$ & $10(8.9 \%)$ & 0.46 \\
\hline \multicolumn{4}{|l|}{ Vital signs and laboratory values } \\
\hline \multicolumn{4}{|l|}{ Blood pressure, mean (SD), $\mathrm{mmHg}$} \\
\hline Systolic & $129.9(15.5)$ & $126.6(15.5)$ & 0.17 \\
\hline Diastolic & $74.5(9.5)$ & $73.2(10.3)$ & 0.41 \\
\hline HbA1c, mean (SD), \% & $7.1(0.8)$ & $7.0(0.7)$ & 0.14 \\
\hline Serum creatinine, mean $(\mathrm{SD}), \mu \mathrm{mol} / \mathrm{L}$ & $85.2(19.5)$ & $93.7(26.0)$ & 0.01 \\
\hline BNP, median [IQR], pg/mL & $30[14-68]$ & $25[12-58]$ & 0.50 \\
\hline Fasting insulin, median $[\mathrm{IQR}], \mu \mathrm{U} / \mathrm{mL}$ & $12.1[8.6-19.0]$ & $13.0[8.6-18.1]$ & 0.96 \\
\hline LDL cholesterol, mean (SD), mg/dL & $87.6(38.0)$ & $85.5(36.6)$ & 0.66 \\
\hline HDL cholesterol, mean (SD), mg/dL & $41.2(10.5)$ & $40.9(9.9)$ & 0.79 \\
\hline Triglycerides, median [IQR], mg/dL & $154.0[113.7-200.9]$ & $161.1[123.9-192.0]$ & 0.61 \\
\hline hsCRP, median [IQR], mg/L & $5.1[2.4-11.7]$ & $6.1[3.7-13.3]$ & 0.19 \\
\hline MMP-9, median $[\mathrm{IQR}], \mu \mathrm{g} / \mathrm{L}$ & $102.1[48.1-202.4]$ & $73.2[38.4-159.9]$ & 0.38 \\
\hline
\end{tabular}


Table 2 Stent size distribution in the groups

\begin{tabular}{|c|c|c|c|c|c|c|}
\hline & \multicolumn{3}{|l|}{ Bare metal stent } & \multicolumn{3}{|l|}{ Drug-eluting stent } \\
\hline & Glipizide $N=21$ & Rosiglitazone $N=21$ & $P$ value & Glipizide $N=40$ & Rosiglitazone $N=31$ & $P$ value \\
\hline Diameter & $2.79 \pm 0.60$ & $3.05 \pm 0.83$ & 0.126 & $2.58 \pm 0.71$ & $2.68 \pm 0.54$ & 0.592 \\
\hline Length & $18.00 \pm 7.20$ & $17.25 \pm 5.10$ & 0.833 & $21.45 \pm 7.81$ & $19.58 \pm 7.02$ & 0.257 \\
\hline
\end{tabular}

In this post-hoc analysis, neither rosiglitazone nor glipizide are randomized groups

On face value these results appear to contrast with the majority of the previously conducted studies, which have all reported significant reductions in the rates of in-stent restenosis in patients treated with thiazolidinediones compared to controls [7-15]. However it must be appreciated that these previous studies have inherent limitations which include: small sample sizes; a single-center location; the lack of independent core lab analysis; short follow-up; and PCI performed using only BMS. The recent POPPS study by Takagi et al. [7] is an exception in view of its multi-center recruitment, and use of an independent core lab; however patients were still only treated with BMS, and follow-up was reported at only 6-months. On the contrary, the current study has distinct advantages in addition to being the largest single assessment to date of in-stent restenosis in patients treated with thiazolidinediones. These additional advantages include medium term follow-up, the use of both bare and drug eluting stents, and IVUS/QCA analysis performed by an independent core lab.

In the recent POPPS study, the neointimal growth index (neointimal volume/stent volume $\times 100$ ) at 6-months amongst patients who were received a BMS, and treatment with pioglitazone and controls was 31 and $40 \%$ respectively [7]; similarly in the current study the respective values of this index at 18-months for rosiglitazone and glipizide were 24 and $19 \%$, respectively. Whilst the results for rosiglitazone are perhaps expected, the change noted with glipizide although welcome is unexpected, and obviously warrants further investigation.

The significance of the different follow-up periods, which were between 6-9 months in the earlier studies and 18-months in the current study, cannot be overstated. Previous IVUS studies have clearly demonstrated that neointimal growth continues to progress up to 18-months after implantation of a BMS, before regressing [18]. This key observation not only highlights the importance of documenting the point in time when IVUS measurements are made, and keeping this in mind when interpreting the IVUS findings; but also indicates the arduous nature of trying to compare results from the current study to previous studies. Nevertheless, in the present study the comparatively lower rates of neointimal growth seen at 18-months, reiterates a comparable effect of both rosiglitazone and glipizide.

In-stent restenosis remains one of the undesired consequences of PCI, and although the introduction of drug eluting stents in 2002 improved rates of restenosis, they have been unable to eliminate it [19]. There is a widely held misconception that restenosis is a benign phenomenon; however it is associated with both morbidity and mortality. In simplistic terms, restenosis increases the requirement for a repeat PCI procedure, which in itself is not risk free. For example a mortality rate of $2.5 \%$ was observed in the Ontario registry in those patients having target vessel revascularisation within a month of their initial PCI procedure [20]. In addition rates of MI related to restenosis have been reported to be between 2 and $19 \%[21,22]$.

In view of this it is no surprise that there is a great desire to identify adjunctive agents which may help reduce in-stent restenosis. This problem is particularly pertinent in diabetic patients owing to the identification of diabetes as an independent predictor of in-stent restenosis [3, 4]. The mechanisms underlying this increased risk are poorly understood, however it is considered amongst others to be the result of a combination of the greater degree of the vascular inflammation, and endothelial dysfunction seen in diabetics [23, 24]. The risk of in-stent restenosis is further compounded in T2DM patients because insulin resistance can aggravate restenosis, through the direct growth-factor like effect of insulin on vascular smooth muscle and neointimal cells [25].

Poor glycaemic control is also implicated in promoting restenosis [26], however previous studies 
Table 3 Results of quantitative coronary angiographic analysis

\begin{tabular}{|c|c|c|c|c|c|c|c|c|c|}
\hline \multirow{2}{*}{$\begin{array}{l}\text { IVUS measurement } \\
\text { Mean (SD), } \mathrm{mm}^{3}\end{array}$} & \multicolumn{3}{|l|}{ Bare metal stent } & \multirow[t]{2}{*}{$P$ value } & \multicolumn{4}{|c|}{ Drug-eluting stent } & \multirow[t]{2}{*}{$P$ value } \\
\hline & \multicolumn{3}{|l|}{$\begin{array}{l}\text { Glipizide } \\
N=21\end{array}$} & & \multicolumn{2}{|c|}{$\begin{array}{l}\text { Glipizide } \\
N=40\end{array}$} & \multicolumn{2}{|c|}{$\begin{array}{l}\text { Rosiglitazone } \\
N=31\end{array}$} & \\
\hline \multicolumn{10}{|l|}{ Vessel volume } \\
\hline Baseline & $302.3(161.4)$ & \multicolumn{2}{|c|}{$245.1(104.3)$} & 0.18 & \multicolumn{2}{|c|}{$278.6(132.6)$} & \multicolumn{2}{|c|}{$302.4(110.1)$} & 0.42 \\
\hline Follow-up & $302.3(160.5)$ & \multicolumn{2}{|c|}{$241.0(110.0)$} & 0.16 & \multicolumn{2}{|c|}{$288.6(141.9)$} & \multicolumn{2}{|c|}{$317.3(102.6)$} & 0.35 \\
\hline Change from baseline & $0.0(29.3)$ & \multicolumn{2}{|c|}{$-4.1(39.8)$} & & \multicolumn{2}{|c|}{$10.0(23.0)$} & \multicolumn{2}{|c|}{$14.9(34.1)$} & \\
\hline $\begin{array}{l}\text { Model-adjusted change } \\
\text { (SE) }\end{array}$ & $\begin{array}{l}8.7(16.6) \\
P=0.60\end{array}$ & \multicolumn{2}{|c|}{9.8 (16.3), $P=0.55$} & & \multicolumn{2}{|c|}{6.7 (13.9) $P=0.62$} & \multicolumn{2}{|c|}{$\begin{array}{c}14.0(14.3) \\
P=0.33\end{array}$} & \\
\hline $\begin{array}{l}\text { Treatment difference } \\
\quad(95 \% \mathrm{CI})\end{array}$ & \multicolumn{3}{|l|}{$1.1(-24.9,27.1)$} & 0.93 & $7.3(-$ & $4,22.0)$ & & & 0.32 \\
\hline Stent volume & & & & & & & & & \\
\hline Baseline & $147.4(81.1)$ & $125.8(53$ & & 0.31 & 140.5 & 4.4) & 152 & $.9(61.0)$ & 0.42 \\
\hline Follow-up & $145.5(78.7)$ & $127.3(60$ & & 0.41 & 145.0 & 5.8) & 155 & $.7(53.4)$ & 0.47 \\
\hline Change from baseline & $-1.9(15.4)$ & $1.5(16.4)$ & & & $4.5(10$ & & 2.8 & (17.3) & \\
\hline $\begin{array}{l}\text { Model-adjusted change } \\
\text { (SE) }\end{array}$ & $\begin{array}{r}-1.2(7.9) \\
P=0.88\end{array}$ & 3.5 (7.6), & $=0.65$ & & $0.3(6$ & $P=0.96$ & & $\begin{array}{l}.4(6.9) \\
=0.95\end{array}$ & \\
\hline $\begin{array}{l}\text { Treatment difference } \\
\quad(95 \% \mathrm{CI})\end{array}$ & $4.7(-7.3,16.6)$ & & & 0.43 & -0.7 & $7.8,6.4)$ & & & 0.84 \\
\hline Plaque behind stent & & & & & & & & & \\
\hline Baseline & $154.9(83.3)$ & $119.3(57$ & & 0.11 & 138.1 & 7.9) & $14 \mathrm{C}$ & $.6(59.7)$ & 0.50 \\
\hline Follow-up & $156.8(85.2)$ & $113.7(54$ & & 0.06 & 143.6 & 3.6) & 161 & $.7(58.7)$ & 0.29 \\
\hline Change from baseline & $1.9(19.1)$ & $-5.6(26$. & & & $5.5(16$ & & 12. & $1(22.4)$ & \\
\hline $\begin{array}{l}\text { Model-adjusted change } \\
\text { (SE) }\end{array}$ & $\begin{array}{c}10.3(10.5) \\
P=0.33\end{array}$ & $6.0(10.6)$ & $P=0.58$ & & $5.7(9$. & $P=0.54$ & 14. & $3(9.7), P=0.15$ & \\
\hline $\begin{array}{l}\text { Treatment difference } \\
(95 \% \text { CI })\end{array}$ & $-4.3(-21.2,12$ & & & 0.61 & $8.6(-$ & $4,18.5)$ & & & 0.09 \\
\hline \%volume of $I H^{*}$ & & & & & & & & & \\
\hline Baseline & $-0.1(0.2)$ & $-0.01(0$. & & 0.25 & -0.3 & & -0 & $.3(0.80)$ & 0.75 \\
\hline Follow-up & $19.7(11.1)$ & $24.1(17.1$ & & 0.33 & $8.0(8$. & & 9.6 & (11.3) & 0.51 \\
\hline Change from baseline & $19.8(11.1)$ & $24.1(17.1$ & & & $8.3(8$. & & 9.8 & (11.3) & \\
\hline $\begin{array}{l}\text { Model-adjusted change } \\
\text { (SE) }\end{array}$ & $\begin{array}{l}19.1(7.2) \\
P=0.01\end{array}$ & $\begin{array}{r}23.9 \\
P=0.0\end{array}$ & & & $\begin{array}{c}19.7(4 \\
P<\end{array}$ & $\begin{array}{l}3), \\
0001\end{array}$ & $\begin{aligned} 21 . \\
P\end{aligned}$ & $\begin{array}{l}0(4.4) \\
<0.0001\end{array}$ & \\
\hline $\begin{array}{l}\text { Treatment difference } \\
\quad(95 \% \mathrm{CI})\end{array}$ & $4.9(-6.2,15.9)$ & & & 0.38 & $1.3(-$ & $2,5.8)$ & & & 0.57 \\
\hline QCA measurement & & Bare metal st & & & $P$ value & Drug-elutin & g st & & $P$ value \\
\hline & & $\begin{array}{l}\text { Glipizide } \\
N=37\end{array}$ & $\begin{array}{l}\text { Rosiglitaz } \\
N=35\end{array}$ & zone & & $\begin{array}{l}\text { Glipizide } \\
N=57\end{array}$ & & $\begin{array}{l}\text { Rosiglitazone } \\
N=44\end{array}$ & \\
\hline In-stent late loss (mm) & & & & & & & & & \\
\hline Mean & & 0.71 & 0.76 & & & 0.25 & & 0.37 & \\
\hline SD & & 0.380 & 0.572 & & & 0.304 & & 0.586 & \\
\hline Model -adjusted Mean & month 18 (SE) & $0.85(0.151)$ & $0.93(0.16$ & 62) & 0.51 & $0.75(0.177)$ & & $0.82(0.183)$ & 0.41 \\
\hline In-stent DS (\%) & & & & & & & & & \\
\hline Mean & & 30.4 & 32.3 & & & 17.9 & & 22.1 & \\
\hline SD & & 15 & 18 & & & 12 & & 20 & \\
\hline Model-adjusted Mean a & month 18 (SE) & $32.98(5.32)$ & $35.92(5.6$ & 678) & 0.50 & $32.57(6.34$ & & $35.82(6.53)$ & 0.28 \\
\hline
\end{tabular}


Table 3 continued

\begin{tabular}{|c|c|c|c|c|c|c|}
\hline \multirow[t]{2}{*}{ QCA measurement } & \multicolumn{2}{|c|}{ Bare metal stent } & \multirow[t]{2}{*}{$P$ value } & \multicolumn{2}{|c|}{ Drug-eluting stent } & \multirow[t]{2}{*}{$P$ value } \\
\hline & $\begin{array}{l}\text { Glipizide } \\
N=37\end{array}$ & $\begin{array}{l}\text { Rosiglitazone } \\
N=35\end{array}$ & & $\begin{array}{l}\text { Glipizide } \\
N=57\end{array}$ & $\begin{array}{l}\text { Rosiglitazone } \\
N=44\end{array}$ & \\
\hline \multicolumn{7}{|l|}{$R V D(m m)$} \\
\hline Mean & 2.62 & 2.58 & & 2.62 & 2.78 & \\
\hline SD & 0.51 & 0.47 & & 0.42 & 0.44 & \\
\hline Model-adjusted Mean at month 18 (SE) & $2.51(0.100)$ & $2.53(0.108)$ & 0.76 & $2.61(0.121)$ & $2.67(0.125)$ & 0.32 \\
\hline \multicolumn{7}{|l|}{$M L D(m m)$} \\
\hline Mean & 1.84 & 1.75 & & 2.15 & 2.27 & \\
\hline SD & 0.59 & 0.56 & & 0.46 & 0.45 & \\
\hline Model-adjusted Mean at month 18 (SE) & $1.68(0.151)$ & $1.60(0.162)$ & 0.50 & $1.78(0.141)$ & $1.79(0.146)$ & 0.86 \\
\hline Binary angiographic restenosis, $n(\%)$ & $4(10.81)$ & $8(22.86)$ & 0.21 & $1(1.75)$ & $2(4.55)$ & 0.58 \\
\hline
\end{tabular}

In this post-hoc analysis, neither rosiglitazone nor glipizide are randomized groups; $* \%$ vol $I H$ percentage volume of intimal hyperplasia

Table 4 Adverse cardiovascular events occurring either ontherapy or post-therapy

\begin{tabular}{lll}
\hline $\begin{array}{l}\text { Patients with } \\
\text { an event, } n(\%)\end{array}$ & $\begin{array}{l}\text { Glipizide } \\
(N=118) \\
(\%)\end{array}$ & $\begin{array}{l}\text { Rosiglitazone } \\
(N=113) \\
(\%)\end{array}$ \\
\hline All-cause death & $3(2.5)$ & $5(4.4)$ \\
Cardiovascular death & $1(0.8)$ & $2(1.8)$ \\
Stroke & $0(0.0)$ & $2(1.8)$ \\
Myocardial infarction & $2(1.7)$ & $5(4.4)$ \\
Nonfatal MI & $1(0.8)$ & $4(3.5)$ \\
Fatal MI & $1(0.8)$ & $1(0.9)$ \\
Cardiovascular death, nonfatal & $2(1.7)$ & $7(6.2)$ \\
$\quad$ stroke, or nonfatal MI & & \\
Coronary revascularisation & $14(11.9)$ & $15(13.3)$ \\
\hline
\end{tabular}

In this post-hoc analysis, neither rosiglitazone nor glipizide are randomized groups

which have reported the benefit of thiazolidinediones in reducing restenosis have indicated that this benefit occurs independently of the drug's effect on glycaemic control [7]. There are many potential mechanisms by which thiazolidinediones may reduce in-stent restenosis including: (a) the inhibition of smooth muscle cell migration and proliferation [27, 28]; (b) the increased apoptosis in vascular smooth muscle cells [29]; (c) a beneficial effect on local inflammation [30, 31]; (d) an anti-thrombotic effect [32]; and (e) a beneficial effect on fasting insulin levels, thereby preventing insulin driven atherosclerosis $[25,33]$.
In the end, it is important to highlight recent concerns associated with rosiglitazone use. Following drug launch, a metanalysis published in 2007 showed, indeed, an increased risk of myocardial infarction and cardiovascular death associated with rosiglitazone [34]. The recent RECORD trial also demonstrated an increased risk of heart failure events in people treated with rosiglitazone [35]. Eventually, the FDA mandated a study comparing rosiglitazone and pioglitazone with placebo, known as TIDE and then stopped the inclusion of the patients. Rosiglitazone has subsequently been removed from the EU market however it remains on available on the US market albeit with severe restrictions.

\section{Limitations}

IVUS analyses were available in half of the patients included in the present study and could not be representative of overall population. Stent design was not pre-specified for the different groups.

\section{Conclusions}

This study indicates that both rosiglitazone and glipizide have a similar effect on neointimal growth at medium term follow-up, a finding that warrants investigation in dedicated randomized trials. 
Acknowledgments This study was funded by GlaxoSmithKline Pharmaceuticals. The authors of this manuscript have certified that they comply with the Principles of Ethical Publishing in the International Journal of Cardiology [36].

Conflict of interest Dr Garcia-Garcia received honoraria from GlaxoSmith- Kline; Dr Garg, Dr Brugaletta and Dr Morocutti have no conflict of interest to declare. Dr Ratner has received grants from AstraZeneca, Bayhill Therapeutics, GlaxoSmithKline, Novo Nordisk, Takeda; served as an advisor to Amylin, AstraZeneca, Novo Nordisk, Roche, Sanofi-Aventis, and Tethys; and holds stock ( $\geq \$ 10,000$ value) in Abbott, Johnson and Johnson, and Merck. Dr. Serruys received honoraria from GlaxoSmith-Kline. Dr Nesto has served on speakers' bureaus for GlaxoSmithKline and Takeda and served as an advisor to GlaxoSmithKline. Drs Kolatkar, Miller, and Huang and B.G. Kravitz are employed by and own stock in GlaxoSmithKline.

Open Access This article is distributed under the terms of the Creative Commons Attribution Noncommercial License which permits any noncommercial use, distribution, and reproduction in any medium, provided the original author(s) and source are credited.

\section{Appendix}

Steering Committee: R. Ratner, P. Fitzgerald (cochairs), C. Cannon, H. Gerstein, R. Nesto, P. Serruys, G-A Van Es, A. Zalewski.

Statistical Data and Analysis Center: Axio Research, Seattle, WA. L. Shemanski, A. Slee.

Endpoint Adjudication Committee: M. Savage (chair), H. Weitz, I. Ahmed.

APPROACH Study Management Team: R.P. Aftring, N. Kolatkar, B. Kravitz, A. Wolstenholme, K. Saarinen, R. Fowler, Janet Hoffman, D. SteeleNorwood, R. Russell,S. Young and former team members Hubert Chou, Steve McMorn, Courtney Kirsch, Bonnie Louridas, Teresa Olivieria, and Debra Mattioli.

APPROACH Statistics and Data Management Team: D. Miller, C. Huang, C. Nguyen, L. Jahnke. Independent Data Monitoring Committee- G. Mintz, J. Lachin (co-chairs), M. Abrahamson, P. Carson, P. Jones.

\section{References}

1. Ratner RE, Cannon CP, Gerstein HC, Nesto RW, Serruys PW, Van Es GA, Kolatkar NS, Kravitz BG, Zalewski A, Fitzgerald PJ (2008) Assessment on the prevention of progression by rosiglitazone on atherosclerosis in diabetes patients with cardiovascular history (approach): Study design and baseline characteristics. Am Heart J 156(6): 1074-1079. doi:10.1016/j.ahj.2008.07.025

2. Gerstein HC, Ratner RE, Cannon CP, Serruys PW, GarciaGarcia HM, van Es GA, Kolatkar NS, Kravitz BG, Miller DM, Huang C, Fitzgerald PJ, Nesto RW Effect of rosiglitazone on progression of coronary atherosclerosis in patients with type 2 diabetes mellitus and coronary artery disease. The assessment on the prevention of progression by rosiglitazone on atherosclerosis in diabetes patients with cardiovascular history trial. Circulation. doi:10.1161/ CIRCULATIONAHA.109.881003

3. Abizaid A, Kornowski R, Mintz GS, Hong MK, Abizaid AS, Mehran R, Pichard AD, Kent KM, Satler LF, Wu H, Popma JJ, Leon MB (1998) The influence of diabetes mellitus on acute and late clinical outcomes following coronary stent implantation. J Am Coll Cardiol 32(3): 584-589. doi:S0735-1097(98)00286-1

4. Lemos PA, Hoye A, Goedhart D, Arampatzis CA, Saia F, van der Giessen WJ, McFadden E, Sianos G, Smits PC, Hofma SH, de Feyter PJ, van Domburg RT, Serruys PW (2004) Clinical, angiographic, and procedural predictors of angiographic restenosis after sirolimus-eluting stent implantation in complex patients: An evaluation from the rapamycin-eluting stent evaluated at rotterdam cardiology hospital (research) study. Circulation 109(11):1366-1370. doi:10.1161/01.CIR.0000121358.26097.06

5. Scheen AJ, Warzee F, Legrand VM (2004) Drug-eluting stents: meta-analysis in diabetic patients. Eur Heart J 25(23): 2167-2168; author reply 2168-2169. doi:10.1016/j.ehj. 2004.07.041

6. Moussa I, Leon MB, Baim DS, O’Neill WW, Popma JJ, Buchbinder M, Midwall J, Simonton CA, Keim E, Wang P, Kuntz RE, Moses JW (2004) Impact of sirolimus-eluting stents on outcome in diabetic patients: A sirius (sirolimuscoated bx velocity balloon-expandable stent in the treatment of patients with de novo coronary artery lesions) substudy. Circulation 109(19):2273-2278. doi:10.1161/01. CIR.0000129767.45513.71

7. Takagi T, Okura H, Kobayashi Y, Kataoka T, Taguchi H, Toda I, Tamita K, Yamamuro A, Sakanoue Y, Ito A, Yanagi S, Shimeno K, Waseda K, Yamasaki M, Fitzgerald PJ, Ikeno F, Honda Y, Yoshiyama M, Yoshikawa J (2009) A prospective, multicenter, randomized trial to assess efficacy of pioglitazone on in-stent neointimal suppression in type 2 diabetes: Popps (prevention of in-stent neointimal proliferation by pioglitazone study). JACC Cardiovasc Interv 2(6):524-531. doi:10.1016/j.jcin.2009.04.007

8. Takagi T, Yamamuro A, Tamita K, Yamabe K, Katayama M, Mizoguchi S, Ibuki M, Tani T, Tanabe K, Nagai K, Shiratori K, Morioka S, Yoshikawa J (2003) Pioglitazone reduces neointimal tissue proliferation after coronary stent implantation in patients with type 2 diabetes mellitus: An intravascular ultrasound scanning study. Am Heart J 146(2):E5. doi:10.1016/S0002-8703(03)00146-7

9. Law RE, Goetze S, Xi XP, Jackson S, Kawano Y, Demer L, Fishbein MC, Meehan WP, Hsueh WA (2000) Expression and function of ppargamma in rat and human vascular smooth muscle cells. Circulation 101(11):1311-1318

10. Choi D, Kim SK, Choi SH, Ko YG, Ahn CW, Jang Y, Lim SK, Lee HC, Cha BS (2004) Preventative effects of 
rosiglitazone on restenosis after coronary stent implantation in patients with type 2 diabetes. Diabetes Care 27(11): 2654-2660. doi:27/11/2654

11. Geng DF, Jin DM, Wu W, Wang Z, Wang JF (2009) Effect of thiazolidinediones on in-stent restenosis in patients after coronary stenting: A meta-analysis of randomized controlled trials. Atherosclerosis 202(2):521-528. doi: 10.1016/j.atherosclerosis.2008.05.029

12. Katayama T, Ueba H, Tsuboi K, Kubo N, Yasu T, Kuroki M, Saito M, Momomura S, Kawakami M (2007) Reduction of neointimal hyperplasia after coronary stenting by pioglitazone in nondiabetic patients with metabolic syndrome. Am Heart J 153(5):762 e761-762 e767. doi:10.1016/j.ahj. 2007.02.022

13. Marx N, Wohrle J, Nusser T, Walcher D, Rinker A, Hombach V, Koenig W, Hoher M (2005) Pioglitazone reduces neointima volume after coronary stent implantation: A randomized, placebo-controlled, double-blind trial in nondiabetic patients. Circulation 112(18):2792-2798. doi:10.1161/CIRCULATIONAHA.105.535484

14. Osman A, Otero J, Brizolara A, Waxman S, Stouffer G, Fitzgerald P, Uretsky BF (2004) Effect of rosiglitazone on restenosis after coronary stenting in patients with type 2 diabetes. Am Heart J 147(5):e23. doi:10.1016/j.ahj.2003. 12.006

15. Nishio K, Sakurai M, Kusuyama T, Shigemitsu M, Fukui T, Kawamura K, Itoh S, Konno N, Katagiri T (2006) A randomized comparison of pioglitazone to inhibit restenosis after coronary stenting in patients with type 2 diabetes. Diabetes Care 29(1):101-106. doi:29/1/101

16. Rodriguez-Granillo GA, Vos J, Bruining N, Garcia-Garcia HM, de Winter S, Ligthart JM, Deckers JW, Bertrand M, Simoons ML, Ferrari R, Fox KM, Remme W, De Feyter PJ (2007) Long-term effect of perindopril on coronary atherosclerosis progression (from the perindopril's prospective effect on coronary atherosclerosis by angiography and intravascular ultrasound evaluation [perspective] study). Am J Cardiol 100(2):159-163. doi:10.1016/j.amjcard. 2007.02.073

17. De Winter SA, Hamers R, Degertekin M, Tanabe K, Lemos PA, Serruys PW, Roelandt JR, Bruining N (2004) Retrospective image-based gating of intracoronary ultrasound images for improved quantitative analysis: The intelligate method. Catheter Cardiovasc Interv 61(1):84-94. doi:10.1002/ccd.10693

18. Aoki J, Colombo A, Dudek D, Banning AP, Drzewiecki J, Zmudka K, Schiele F, Russell ME, Koglin J, Serruys PW (2005) Peristent remodeling and neointimal suppression 2 years after polymer-based, paclitaxel-eluting stent implantation: Insights from serial intravascular ultrasound analysis in the taxus ii study. Circulation 112(25): 3876-3883. doi:10.1161/CIRCULATIONAHA.105.558601

19. Stettler C, Wandel S, Allemann S, Kastrati A, Morice MC, Schomig A, Pfisterer ME, Stone GW, Leon MB, de Lezo JS, Goy JJ, Park SJ, Sabate M, Suttorp MJ, Kelbaek H, Spaulding C, Menichelli M, Vermeersch P, Dirksen MT, Cervinka P, Petronio AS, Nordmann AJ, Diem P, Meier B, Zwahlen M, Reichenbach S, Trelle S, Windecker S, Juni P (2007) Outcomes associated with drug-eluting and bare-metal stents: A collaborative network meta-analysis.
Lancet 370(9591):937-948. doi:10.1016/S0140-6736(07) 61444-5

20. Tu JV, Bowen J, Chiu M, Ko DT, Austin PC, He Y, Hopkins R, Tarride JE, Blackhouse G, Lazzam C, Cohen EA, Goeree R (2007) Effectiveness and safety of drug-eluting stents in ontario. N Engl J Med 357(14):1393-1402. doi: 10.1056/NEJMoa071076

21. Windecker S, Juni P (2008) Safety of drug-eluting stents. Nat Clin Pract Cardiovasc Med 5(6):316-328. doi: 10.1038/ncpcardio1189

22. Daemen J, Wenaweser P, Tsuchida K, Abrecht L, Vaina S, Morger C, Kukreja N, Juni P, Sianos G, Hellige G, van Domburg RT, Hess OM, Boersma E, Meier B, Windecker S, Serruys PW (2007) Early and late coronary stent thrombosis of sirolimus-eluting and paclitaxel-eluting stents in routine clinical practice: Data from a large two-institutional cohort study. Lancet 369(9562):667-678. doi:10.1016/S0140-67 36(07)60314-6

23. Kereiakes DJ, Young JJ (2005) Percutaneous coronary revascularization of diabetic patients in the era of drugeluting stents. Rev Cardiovasc Med 6(Suppl 1):S48S58

24. Aronson D, Bloomgarden Z, Rayfield EJ (1996) Potential mechanisms promoting restenosis in diabetic patients. J Am Coll Cardiol 27(3):528-535. doi:0735-1097(95)00 496-3

25. Beckman JA, Creager MA, Libby P (2002) Diabetes and atherosclerosis: Epidemiology, pathophysiology, and management. JAMA 287(19):2570-2581. doi:jrv10119

26. Corpus RA, George PB, House JA, Dixon SR, Ajluni SC, Devlin WH, Timmis GC, Balasubramaniam M, O'Neill WW (2004) Optimal glycemic control is associated with a lower rate of target vessel revascularization in treated type ii diabetic patients undergoing elective percutaneous coronary intervention. J Am Coll Cardiol 43(1):8-14. doi: S073510970301324X

27. Goetze S, Xi XP, Graf K, Fleck E, Hsueh WA, Law RE (1999) Troglitazone inhibits angiotensin ii-induced extracellular signal-regulated kinase $1 / 2$ nuclear translocation and activation in vascular smooth muscle cells. FEBS Lett 452(3):277-282. doi:S0014-5793(99)00624-9

28. Yasunari K, Kohno M, Kano H, Yokokawa K, Minami M, Yoshikawa J (1997) Mechanisms of action of troglitazone in the prevention of high glucose-induced migration and proliferation of cultured coronary smooth muscle cells. Circ Res 81(6):953-962

29. Aizawa Y, Kawabe J, Hasebe N, Takehara N, Kikuchi K (2001) Pioglitazone enhances cytokine-induced apoptosis in vascular smooth muscle cells and reduces intimal hyperplasia. Circulation 104(4):455-460

30. Ishibashi M, Egashira K, Hiasa K, Inoue S, Ni W, Zhao Q, Usui M, Kitamoto S, Ichiki T, Takeshita A (2002) Antiinflammatory and antiarteriosclerotic effects of pioglitazone. Hypertension 40(5):687-693

31. Kasai T, Miyauchi K, Yokoyama T, Kajimoto K, Sumiyoshi K, Kubota N, Ikeda E, Daida H (2008) Pioglitazone attenuates neointimal thickening via suppression of the early inflammatory response in a porcine coronary after stenting. Atherosclerosis 197(2):612-619. doi:10.1016/j. atherosclerosis.2007.08.030 
32. Li D, Chen K, Sinha N, Zhang X, Wang Y, Sinha AK, Romeo F, Mehta JL (2005) The effects of ppar-gamma ligand pioglitazone on platelet aggregation and arterial thrombus formation. Cardiovasc Res 65(4):907-912. doi: 10.1016/j.cardiores.2004.11.027

33. Takagi T, Yoshida K, Akasaka T, Kaji S, Kawamoto T, Honda Y, Yamamuro A, Hozumi T, Morioka S (2000) Hyperinsulinemia during oral glucose tolerance test is associated with increased neointimal tissue proliferation after coronary stent implantation in nondiabetic patients: A serial intravascular ultrasound study. J Am Coll Cardiol 36(3):731-738. doi:S0735-1097(00)00799-3
34. Nissen SE, Wolski K (2007) Effect of rosiglitazone on the risk of myocardial infarction and death from cardiovascular causes. N Engl J Med 356(24):2457-2471. doi:10.1056/ NEJMoa072761

35. Komajda M, McMurray JJ, Beck-Nielsen H, Gomis R, Hanefeld M, Pocock SJ, Curtis PS, Jones NP, Home PD (2010) Heart failure events with rosiglitazone in type 2 diabetes: Data from the record clinical trial. Eur Heart $\mathbf{J}$ 31(7):824-831. doi:10.1093/eurheartj/ehp604

36. Coats AJ (2009) Ethical authorship and publishing. Int $\mathbf{J}$ Cardiol 131(2):149-150. doi:10.1016/j.ijcard.2008.11.048 